\title{
Development of Genetically Modified Tumor Cell Containing Co-stimulatory Molecule
}

\author{
Hong Sung Kim ${ }^{\dagger}, *$ \\ Department of Biomedical Laboratory Science, Korea Nazarene University, Cheonan 31172, Korea
}

\begin{abstract}
Cancer immunotherapy using gene-modified tumor cells is safe and customized cancer treatment method. In this study, we made gene-modified tumor cells by transferring costimulatory molecules, 4-1BBL and OX40L, into tumor cells using lentivirus vector, and identified anti-cancer effect of gene-modified tumor cells in CT26 mouse colorectal tumor model. We construct pLVX-puro-4-1BBL, -OX40L vector for lentivirus production and optimized the transfection efficiency and transduction efficiency. The transfection efficiency is maximal at DNA:cationic polymer $=1: 0.5$ and DNA $2 \mu \mathrm{g}$ for lentivirus production. Then, the lentiviral including 4-1BBL and OX40L was used to deliver CT26 mouse tumor cells to establish optimal delivery conditions according to the amount of virus. The transduction efficiency is maximal at $500 \mu \mathrm{L}$ volume of lentiviral stock without change in cell shape or growth rate. CT26-4-1BBL, CT26-OX40L significantly inhibited the tumor growth compare with CT26-WT or CT26- $\beta$-gal cell line. These data showed the possibility the use of genetically modified tumor cells with costimulatory molecule as cancer immunotherapy agent.
\end{abstract}

Key Words: Genetically modified tumor cell, Gene transfection, Transfection efficiency, Tumor growth pattern

\section{INTRODUCTION}

Recently, the development of a therapeutic method using the immune system of the human body for the treatment of cancer has been attempted. However, despite the presence of immune surveillance for tumors, tumors also grow in the normal immune system. Various treatment strategies are being researched and developed for cancer immunotherapy. Many therapies have been developed such as monoclonal antibody therapy (Weiner et al., 2009), adoptive cell therapy (Perica et al., 2015), tumor cell vaccines (Hanna, 2012), cytokine administration (Lee and Margolin, 2011), Dendritic cell vaccines (van Willigen et al., 2018). Among these, tumor cell vaccine is the safest and most appropriate immunotherapy method for patient-specific treatment.

Whole tumor cell vaccines have been tested in clinical and preclinical studies (Keenan and Jaffee, 2012; Srivatsan et al., 2014; Pan et al., 2018; Wang et al., 2018), and have several advantages in cancer immunotherapy (Wang et al., 2018). Whole tumor cell vaccines offer tumor antigens and tumor associated antigen to elicit tumor-specific immunity (Chiang et al., 2015; Allahverdiyev et al., 2018). Whole tumor cell vaccines facilitate a high-efficiency antitumor response (Si et al., 2017). Immune stimulation by whole tumor cell vaccines could promote a stronger antitumor effect and long-term memory through CD8+ T cells (Luo et al., 2019). Many phase I and II clinical trials have reported that

Received: December 24, 2019 / Accepted: December 24, 2019

*Professor.

'Corresponding author: Hong Sung Kim. Department of Biomedical Laboratory Science Korea Nazarene University, 48 Wolbong Ro, Seobuk-Gu, Cheonan-City, Chung Nam 31172, Korea.

Tel: +82-41-570-4165, Fax: +82-41-570-4258, e-mail: hskim@ kornu.ac.kr

(C) The Korean Society for Biomedical Laboratory Sciences. All rights reserved.

(c) This is an Open Access article distributed under the terms of the Creative Commons Attribution Non-Commercial License (http://creativecommons.org/licenses/by-nc/3.0/) which permits unrestricted non-commercial use, distribution, and reproduction in any medium, provided the original work is properly cited. 
whole tumor cell vaccines had significant results in clinical trials (Dillman et al., 2018). However, phase III clinical trials of whole tumor cell vaccines usually fail to produce significant clinical effect (de Gruijl et al., 2008; Giaccone et al., 2015). Many studies have shown that the lack of tumor antigen and immunosuppression caused by the tumor itself may be the main cause of the failure of clinical trial (Goldman and DeFrancesco, 2009; Vermaelen, 2019). Therefore, in order to improve the antitumor effect of whole tumor cell vaccines, addition of other approach is required. Antitumor vaccines with genetically modified tumor cells, which is whole cell vaccine with cytokine GM-CSF (Klein et al., 2000; Hege et al., 2006), have already proven to be effective in application to some types of cancer in animal models (Couch et al., 2003; Miguel et al., 2013), and some of them are being tested in clinical trials (Eager and Nemunaitis, 2005; Nemunaitis et al., 2006; Lipson et al., 2015; Curry et al., 2016). However, tumor treatment using tumor cells still needs to improve the therapeutic effect even more effectively.

Because tumor cell was detected and eliminated by host immune cells, and increased immune response represent good prognosis to cancer patients, it is actively studying many cancer immunotherapy methods using host immune system to minimize the side effect of treatment method and to maximize therapeutic effect. Immune response against tumors are needed by $\mathrm{T}$ cell receptor recognition of tumor associated antigen on MHC molecules. Full activation of T cells requires costimulatory signals, which induce T cell expansion and differentiation to effector and memory cells. 4-1BBL (CD137) and OX40L are members of TNF superfamily and play a critical role in the regulation of pleotropic immune effects.

4-1BBL is a T-cell costimulatory molecule and binds to 4-1BB on activated T cells. 4-1BBL functions T cell clonal expansion and maintenance of long-term immune memory, likely to be critical for tumor rejection (Zhang et al., 2003; Bukczynski et al., 2004; Cheuk et al., 2004). Also, 4-1BBL signaling make effector $\mathrm{T}$ cells resistant to regulatory $\mathrm{T}$ cells (Madireddi et al., 2012). Consistent with this hypothesis, adoptive transfer of $\mathrm{T}$ cells expressing 4-1BBL resulted in potent tumor rejection (Stephan et al., 2007). Systemic administration of agonistic anti-4-1BB monoclonal antibodies enhanced tumor immunity and tumor rejection in a murine melanoma tumor model (May et al., 2002; Vinay and Kwon, 2012). We have previously shown that an oncolytic vaccinia virus expressing 4-1BBL had significant antitumor activity in a carcinoembryonic antigen transgenic murine carcinoma model (Kim et al., 2009).

The ligand of OX40 (OX40L, CD252, TNFSF4) is not constitutively expressed but can be induced on professional antigen presenting cells (APC) (Webb et al., 2016). OX40L also promotes effector $\mathrm{T}$ cell expansion and survival, maintenance of memory $\mathrm{T}$ cell, suppression of regulatory $\mathrm{T}$ cells (Croft et al., 2009; Deng et al., 2019). It has reported that combination therapy with OX40L fusion protein inhibit metastasis in mouse model (Malamas et al., 2017).

In this study, we hypothesized that $4-1 \mathrm{BBL}$ or OX40L expression in tumor cells result in tumor growth inhibition as genetically modified tumor cells. To identify this hypothesis, we constructed a lentiviral vector containing two immune co-stimulatory molecules, 4-1BBL and OX40L, and established 4-1BBL or OX40L expressed tumor cell line to identify anti-tumor effect of 4-1BBL or OX40L.

\section{MATERIALS AND METHODS}

\section{Mice}

6 8 week old female $B a l b / c$ mice were purchased from OrientBio (Korea). Mice were housed and maintained under pathogen-free conditions and treated according to approved institutional protocols for animal care.

\section{Cell lines}

Lenti-X 293 T cell line were obtained from Clontech (Mountain View, CA), and were grown in DMEM containing 10\% Tet system approved FBS, 10 mM L-glutamine, $100 \mathrm{U} /$ $\mathrm{mL}$ Penicillin/streptomycin. CT26 mouse colorectal cancer cell lines were obtained from the American Type Culture Collection (Manassas, VA), and were grown in MEM containing 10\% FBS, $10 \mathrm{mM}$ L-glutamine, $100 \mathrm{U} / \mathrm{mL}$ Penicillin /streptomycin. 

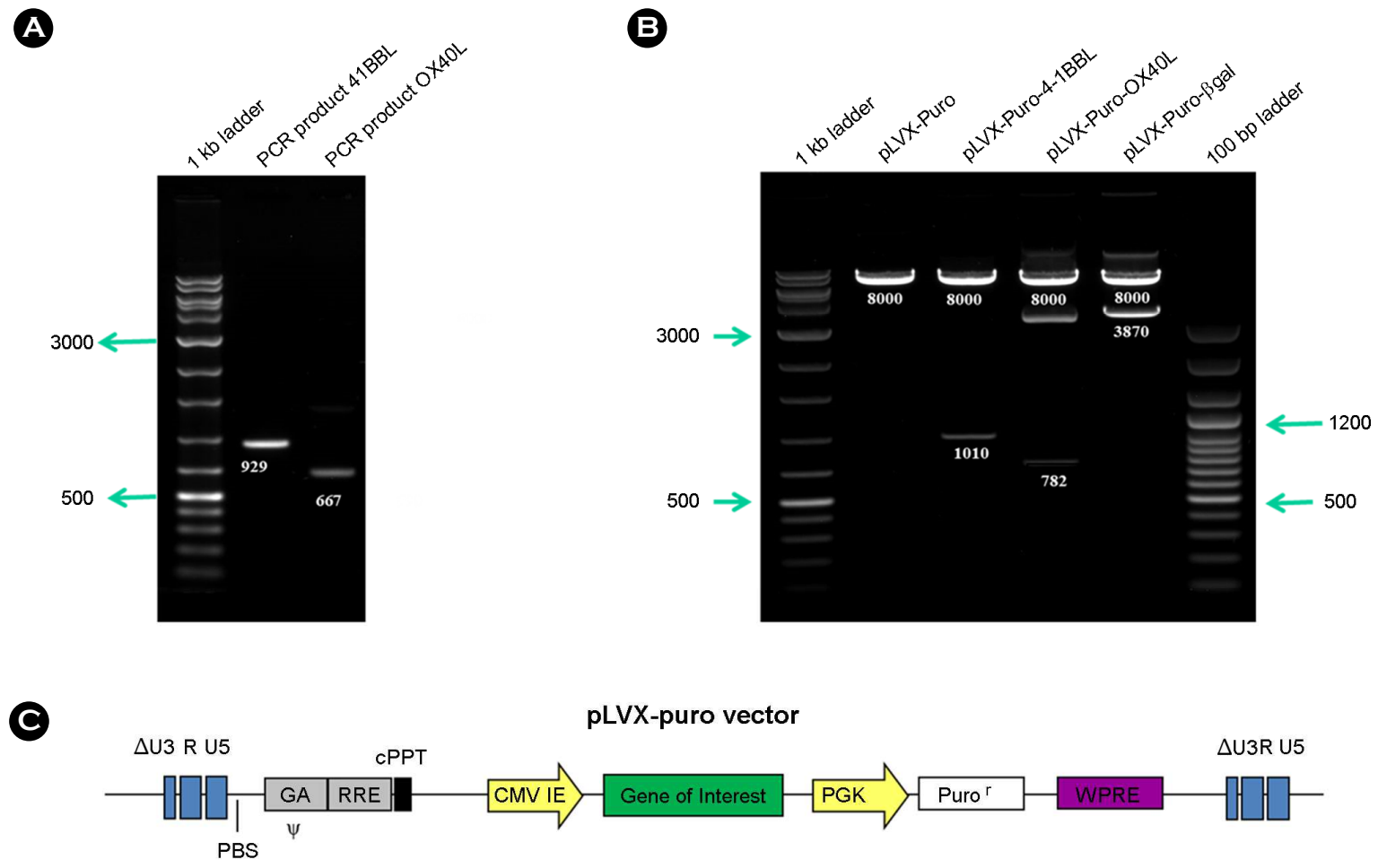

Fig. 1. Construction of Lentivirus vector with 4-1BBL and OX40L. A. PCR product of 4-1BBL (929 bp), OX40L (667 bp) from plasmid DNA, B. pLVX-puro vector containing 4-1BBL, OX40L, and $\beta$-gal gene, C. Scheme of pLVX-puro vector.

\section{Construction of pLVX-puro 4-1BBI and pLVX-puro- OX40L}

pDC201-4-1BBL (ATCC 68682) were obtained from ATCC and pcDNA3.1-OX40L were obtained from Dr. Howard L. Kaufman. pCMV-ßgal was obtained from Clontech. Each 4-1BBL (929 bp) (forward primer 5-ATGGACCAGCACACACTTGA-3, reverse primer 5-TCATTCCCATGGGTTGTCGG-3) or OX40L (667 bp) (forward primer 5-GCTGTATCTCCTCTGCAGCCC-3, reverse primer 5CGAGAAAGAACCTGTGTCCCG-3) gene was amplified by PCR and is inserted by pCR2.1-Topo vector (3,900 bp). pLVX-puro vector ( $8,102 \mathrm{bp}$ ) and Topo-4-1BBL gene is digested by EcoRI, and then is cloned into pLVX-puro vector. pLVX-puro vector and Topo-OX40L is digested by BamHI/ $\mathrm{Xba \textrm {I }}$, and then is cloned into pLVX-puro vector. The final construct is named by pLVX-puro-4-1BBL (9,049 bp) or OX40L ( 8,857 bp). pLVX-puro vector and pCMV- $\beta$ gal is

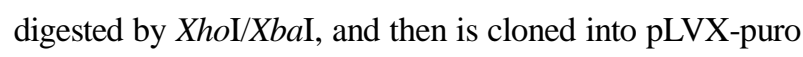
vector. pLVX-puro- $\beta$-gal was used by control vector (Fig
1). Each gene inserted was confirmed by DNA sequencing.
Producing Lentivirus from pLVX-puro 4-1BBI, -OX40L, and - $\beta$-gal

Production of lentivirus is followed by Lenti-X lentiviral expression system user manual (Clontech). Briefly, approximately $24 \mathrm{~h}$ before transfection, Lenti-X $293 \mathrm{~T}$ cells $\left(3 \times 10^{5}\right.$ cells/ 6 well plate, $5 \times 10^{6}$ cells/ $100 \mathrm{~mm}$ dish) were plated, and incubated at $37^{\circ} \mathrm{C}, 5 \% \mathrm{CO}_{2}$. The various DNA amount and DNA;Xfect polymer ratio formulations were added onto the cells in serum-free media, which were then incubated further for $4 \mathrm{~h}$. After transfection, the cell culture medium containing the lipoplexes was replaced with a fresh Tet System Approved FBS-containing medium and the transfected cells were incubated for an additional $48 \mathrm{~h}$ and harvested the lentiviral supernatants and filtered through a $0.45 \mu \mathrm{m}$ filter to remove cellular debris. Virus production was verified with Lenti-X GoStix ${ }^{\mathrm{TM}}$, then used the virus to transduce target cells, or aliquot and store at $-80^{\circ} \mathrm{C}$. 


\section{Transducing CT26 cell line using Lenti-X virus con-} taining 4-1BBL, OX40L, $\beta$-gal

CT26 cells $\left(5 \times 10^{6}\right.$ cells $)$ were plated in $100 \mathrm{~mm}$ dish at $18 \mathrm{~h}$ before transduction. Thawed aliquots of lentiviral stock or fresh lentiviral stock prepared from packaging cells were mixed gently, and adjust various volume of lentiviral stock in the target cell to accommodate the addition of virus and polybrene ( $4 \mu \mathrm{g} / \mathrm{mL}$ ) (Sigma-Aldrich). Dilute the lentiviral stock with medium. Prepared viral supernatant (total $3 \mathrm{~mL}$ ) was added to the cells and transduced for $24 \mathrm{~h}$. And then, the virus-containing transduction medium was removed and replaced it with fresh Tet system approved FBS-containing growth medium, and continued to incubate the cells for $48 \mathrm{~h}$ to allow gene product to express in the target cells and proceed with selection using puromycin $(10 \mu \mathrm{g} / \mathrm{mL})$ for 2 weeks.

\section{Identification of 4-1BBL, $\mathrm{OX} 40 \mathrm{~L}, \beta$-gal gene expression}

Lenti-X-4-1BBL, -OX40L transduced CT26 cells labeled with the following mAbs: allophycocyanin-conjugated CD4, F4/80, and phycoerythrin-conjugated 4-1BBL, OX40L and FITC-conjugated MHC class I. All antibodies were purchased from eBiosciences (San Diego, CA). Samples were acquired using a FACSCalibur flow cytometer and CELL-

\section{(A)}
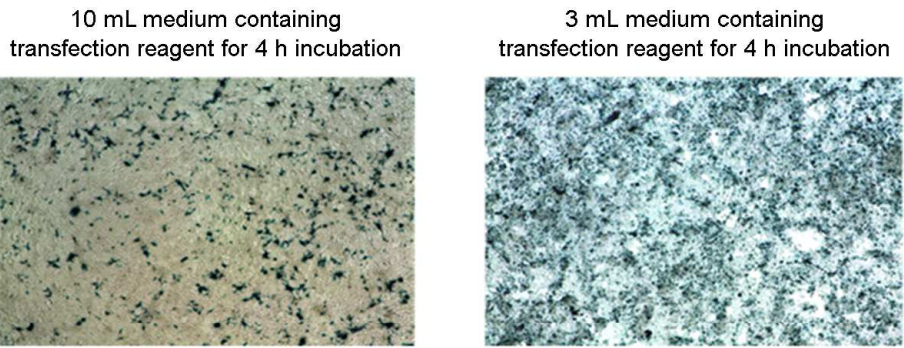

B

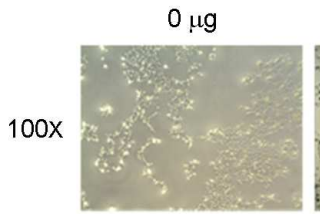

$0.5 \mu \mathrm{g}$

$1 \mu \mathrm{g}$

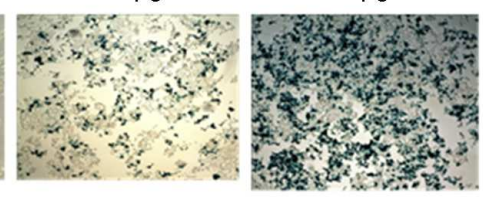

$2 \mu \mathrm{g}$

$3 \mu \mathrm{g}$
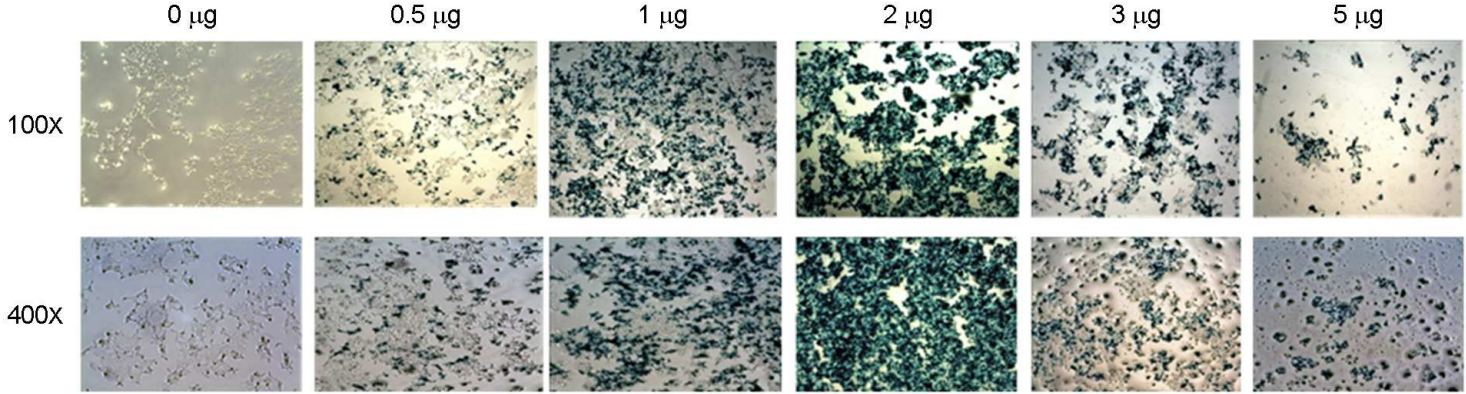

C

DNA:Polymer $\quad 0 \mu \mathrm{L}$
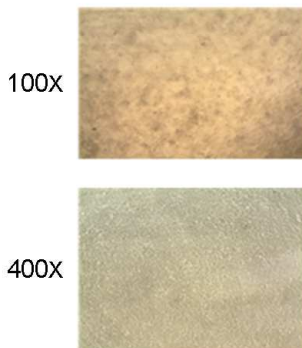

1:0.1
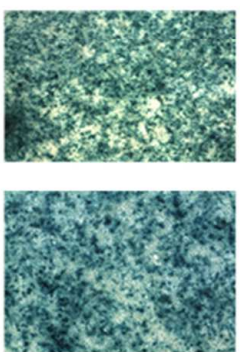

$1: 0.25$
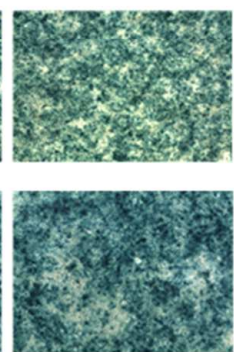

$1: 0.5$
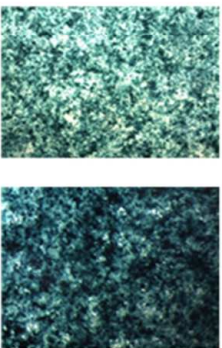

$1: 1$
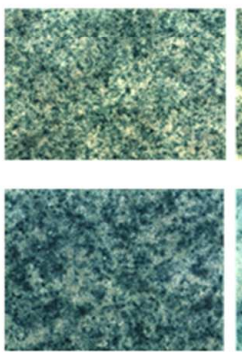

$1: 2.5$
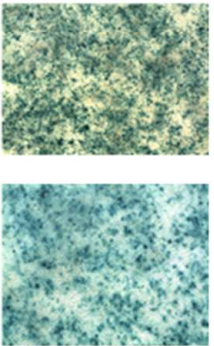

Fig. 2. Identification of transfection efficiency for Lentivirus production. DNA:Xfect polymer were transfected into Lenti-X 293T cells. A. transfection efficiency dependent on medium volume in $100 \mathrm{~mm}$ dish (DNA:polymer ratio=1:1), B. transfection efficiency dependent on DNA amounts in 6 well plate (DNA:polymer ratio=1:1), C. transfection efficiency dependent on DNA;polymer ratio in 6 well plate $(\mathrm{DNA}=2 \mu \mathrm{g})$. 
quest software. Lenti-X- $\beta$-gal transduced CT26 cells were identified by $\beta$-gal staining and microscopy.

\section{Tumor studies and statistical analysis}

CT26 mouse colorectal cancer cells $\left(2 \times 10^{5}\right)$ in $100 \mu \mathrm{L}$ PBS were implanted subcutaneously on the right flank of $\mathrm{Balb} / \mathrm{c}$ mice. Tumors were measured in two dimensions in a blinded fashion using calipers as follows: tumor area $\left(\mathrm{mm}^{3}\right)$ $=$ length $\times$ width $\times$ width. All experiments were repeated two or three times. The data are described as the means \pm SEM. The values were calculated by the Student's $t$-test. Each assay was performed by three independent experiments. $P$ value $(P<0.05)$ was defined as statistically significant.

\section{RESULTS}

\section{Transfection efficiency for lentivirus production}

To identify the transfection efficiency of Xfect polymer for lentivirus production, various DNA amount, DNA: polymer ratio, or media volume were prepared and tested in Lenti-X-293 cells. After a $4 \mathrm{~h}$ transfection and an additional $48 \mathrm{~h}$ incubation, $\beta$-gal expression in the cells was measured by a $\beta$-gal staining assay. As is shown in Fig. $2 \mathrm{~A}$, when $7 \mu \mathrm{g}$ of pDNA complexed to the Xfect polymer (DNA:polymer ration=1:1) were added to Lenti-X293 cells in $100 \mathrm{~mm}$ dish, transfection efficiency of $3 \mathrm{~mL}$ media volume is superior to that of $10 \mathrm{~mL}$ media volume. When various amounts of pDNA complexed to the Xfect polymer (DNA/polymer ratio $=1: 1)$ were added in 6 well plates, $\beta$-gal expression was nearly maximal at $2 \mu \mathrm{g}$ of pDNA and showed cell toxicity at higher DNA amount (Fig. 2B). When various amounts of Xfect polymer complexed to $2 \mu \mathrm{g}$ DNA amount were added in 6 well plates to find the optimal ratio for in vitro transfection, $\beta$-gal expression was maximal at a 1:0.5 ratio of DNA and polymer, and excess addition of polymer decreased the transfection efficiency (1:2.5 ratio of DNA:

(A)

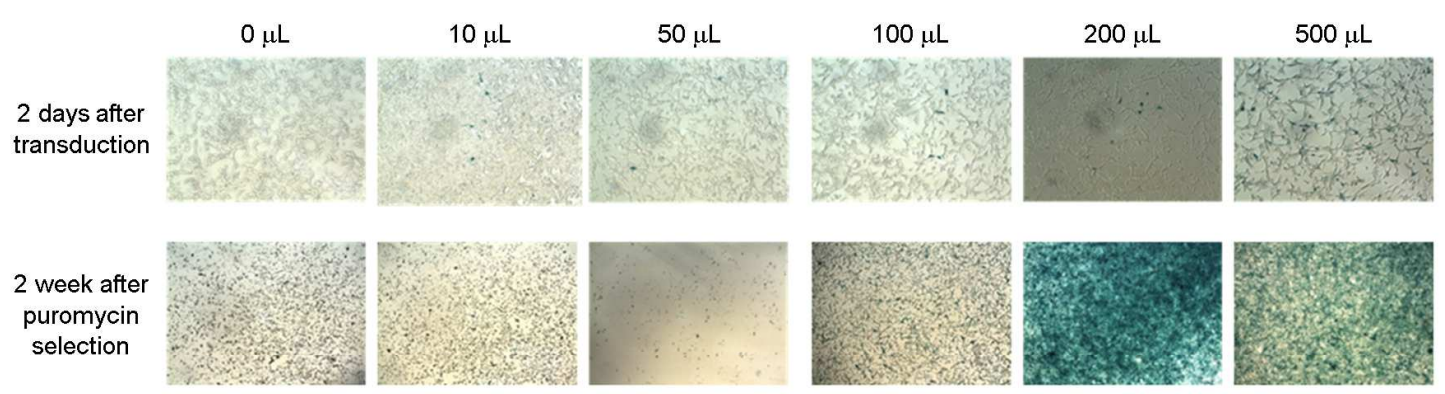

B
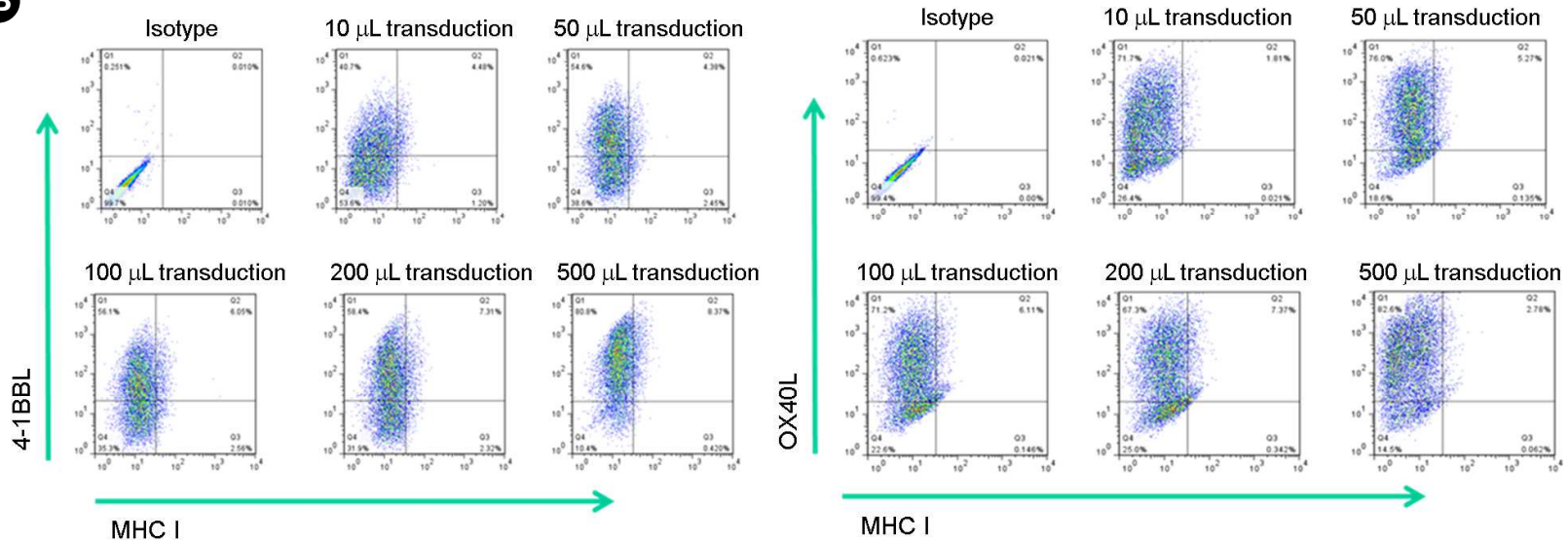

Fig. 3. Identification of transduction efficiency of Lenti-X-4-1BBL, -OX40L, and - $\beta$-gal. The various volume of lentiviral stock were transduced in CT26 cells and lentivirus transduced cells were selected by puromycin. Transduction efficiency were identified two week later. A. $\beta$-gal expression by $\beta$-gal staining, B. 4-1BBL and OX40L expression by FACS analysis 2 weeks after transduction. 
polymer) (Fig. 2C). Under the same transfection conditions, media volume, appropriate DNA amount, DNA:polymer ratio, are important factor for the efficient transfection.

\section{Transduction efficiency of Lentivirus and identification of gene expression}

To identify the transduction efficiency of Lenti-X-4- 1BBL, -OX40L, $-\beta$-gal for production of genetically modified tumor cell, various volume of lentiviral stock were tested in CT26 cells. $\beta$-gal expression of CT26 cell with $\beta$-gal gene (CT26$\beta$-gal) was identified by $\beta$-gal staining at $48 \mathrm{~h}$ after transduction. $\beta$-gal expression is shown to all volume of lentiviral stock, but transduction efficiency is very low. After puro- mycin $(10 \mu \mathrm{g} / \mathrm{mL})$ selection for 2 weeks, $\beta$-gal expression was nearly maximal at $200 \mu \mathrm{L}$ volume of lentiviral stock (Fig. 3A). In case of CT26 cell with 4-1BBL (CT26-4-1BBL) or -OX40L (CT26-OX40L), gene expression is maximal at $500 \mu \mathrm{L}$ volume of lentiviral stock (Fig. 3B). All transduced cell was selected for additional 2 week using puromycin, we used CT26 cells with $100 \%$ gene expression for animal tumor model.

\section{Tumor growth pattern of genetically modified tumor cell}

To determine if genetically modified tumor cells with 4-1BBL or OX40L could be used as cancer immunotherapy agent, we inoculated CT26-wildtype (CD26-WT), CT26-
(A)

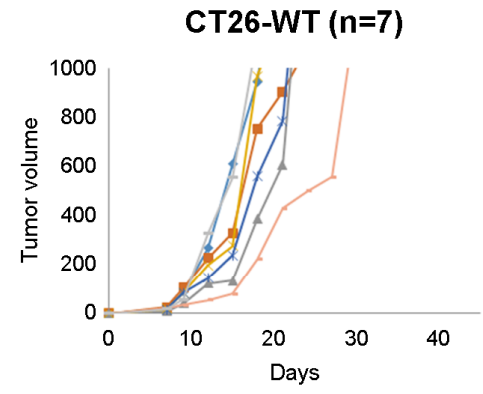

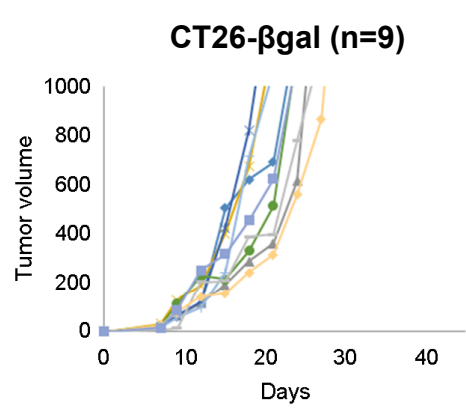

CT26-4-1BBL $(n=9)$

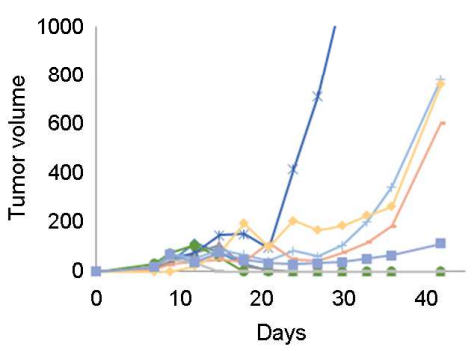

CT26-OX40L $(n=8)$

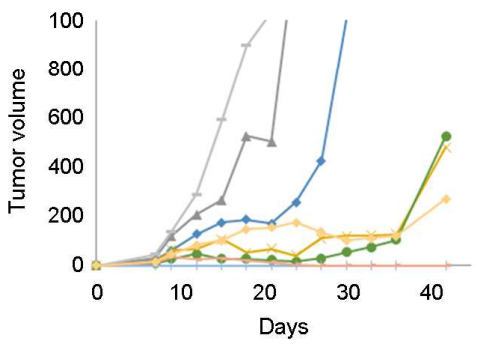

CT26-4-1BBL + CT26-OX40L

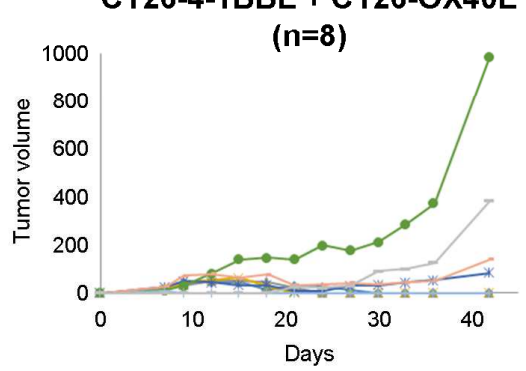

B

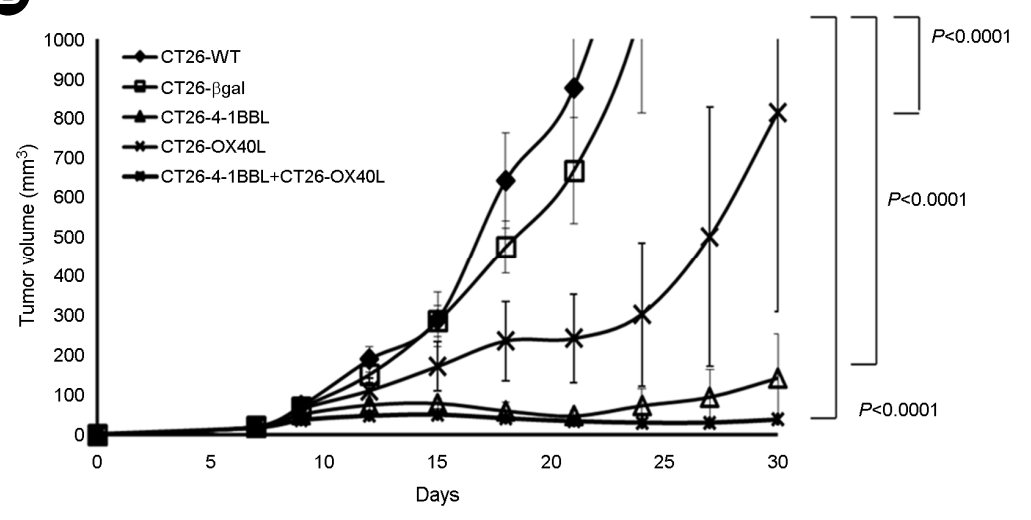

Fig. 4. Inhibition of Tumor Growth by Inoculation of gene modified tumor cells with 4-1BBL and OX40L. After subcutaneous implantation of CT26 cells $\left(2 \times 10^{5}\right.$ cell/100 $\mu$ L PBS $)$ with $\beta$-gal, 4-1BBL, OX40L on the flank of Balb/c female mice, tumor size was measured every third day. A. tumor growth pattern of individual mice in each, B. The average tumor volume of each group. $* * *: P<0.01$ (compared to CT26- $\beta$ gal). 
$\beta$-gal, CT26-4-1BBL, CT26-OX40L cells into the flank of $\mathrm{Balb} / \mathrm{c}$ mice. A small palpable tumor was generally present within 7 days. As expected, CT26-4-1BBL, CT26-OX40L, and CT26-4-1BBL+CT26-OX40L showed significant tumor growth inhibition when compared with CT26-WT or CT26$\beta$-gal $(P<0.0001$; Fig. 4A). CT26-4-1BBL and CT26-4$1 \mathrm{BBL}+\mathrm{CT} 26-\mathrm{OX} 40 \mathrm{~L}$ had an increase in tumor growth inhibition compared with CT26-OX40L, although it is not significant. Furthermore, CT26-4-1BBL, CT26-OX40L, and CT26-4-1BBL+CT26-OX40L bearing mice had smaller tumors, and were shown to have complete regression (CT264-1BBL:4 tumor free mice, CT26-OX40L:2 tumor free mice, CT26-4-1BBL+CT26-OX40L:4 tumor free mice on day 42) (Fig. 4B). On the other hand, CT26-OX40L showed a tumor inhibitory effect, but compared with CT26-4-1BBL or CT264-1BBL+CT26-OX40L, was observed that the variation between the mice is severe.

\section{DISCUSSION}

In this study, we demonstrate costimulatory molecules 4-1BBL and OX40L were transferred into tumor cells using lentiviral gene transfer vectors to form genetically modified tumor cells and confirm whether the genetically modified tumor cells have tumor suppressive effects in tumor animal models.

At first, we constructed pLVX-puro-4-1BBL, -OX40L, - $\beta$-gal vector and optimized the transfection efficiency for lentivirus production and transduction efficiency of LentiX-4-1BBL, -OX40L, - $\beta$-gal. The immune stimulation molecules 4-1BBL and OX40L genes were obtained in order to prepare genetically modified tumor cells, and plasmid DNA for making lentiviruses was obtained through gene recombination. This was confirmed through agarose electrophoresis and DNA sequencing (Fig. 1).

For identification of transfection efficiency, transfection media volume, the amount of DNA and DNA:cationic polymer ratio were considered. In case of transfection media volume, the less volume of transfection media is superior to the more volume. In our hands, less than $3 \mathrm{~mL}$ of transfection media volume is not appropriate for transfection volume of $100 \mathrm{~mm}$ dish. The less transfection volume may be helpful to contact between DNA: cationic polymer complex and cell. In case of the amount of DNA, transfection efficiency is dependent on the amount of DNA, but more than $3 \mu \mathrm{g}$ of DNA showed the cell toxicity. In case of DNA: cationic polymer ratio, transfection efficiency is dependent on the amount of cationic polymer, but more than 1:1 of DNA:cationic polymer ratio showed a decreased transfection efficiency. The transfection efficiency for lentivirus production is maximal at DNA: cationic polymer $=1: 0.5$ and DNA $2 \mu \mathrm{g}$ (Fig. 2). Condition optimization of transfection efficiency is very important to efficient lentiviral production (Tang et al., 2015).

Secondly, the lentivirus including 4-1BBL, OX40L, and $\beta$-gal was used to deliver CT26 mouse tumor cells to establish optimal delivery conditions according to the volume of virus stock. In case of transduction of Lenti-X- $\beta$-gal, there is no difference of $\beta$-gal expression among various volume of viral stock. And, 2 weeks after transduction, $\beta$-gal expression increased by volume dependent manner until $200 \mu \mathrm{L}$ of volume, but decreased at $500 \mu \mathrm{L}$ of volume (Fig. 3A). In case of transduction of Lenti-X-4-1BBL, or -OX40L, each gene expression increased by dependent on volume of viral stock. The transduction efficiency is maximal at $500 \mu \mathrm{L}$ volume of lentiviral stock without change in cell shape or growth rate (Fig. 3B). These data showed that gene expression by lentivirus transduction is various according to the type of gene. Optimal transduction efficiency should be established through various conditions and further studied.

Finally, tumor growth pattern by inoculating genetically modified tumor cells (CT26-WT, CT26-beta gal, CT26-41BBL, CT26-OX40L) on Balb/c mice was confirmed. CT264-1BBL, CT26-OX40L, and CT26-4-1BBL+CT26-OX40L showed a significant tumor growth inhibitory effect compare to CT26 -WT, CT26-beta gal. On day 24, most of mice with CT26-WT or CT26- $\beta$-gal has tumor volume beyond $1,000 \mathrm{~mm}^{3}$, but most of mice with CT26-4-1BBL or CT26OX40L or CT26-4-1BBL+CT26-OX40L has no tumor volume beyond $1,000 \mathrm{~mm}^{3}$. On day 42 , all of mice with CT26WT or CT26- $\beta$-gal has tumor volume beyond $2,000 \mathrm{~mm}^{3}$, but only 1 mice with CT26-4-1BBL and 3 mice of CT26OX40L have tumor volume beyond $2,000 \mathrm{~mm}^{3}$. In case of mice with CT26-4-1BBL+CT26-OX40L, there was no mice 
with tumor volume beyond 2,000 $\mathrm{mm}^{3}$. Even $20 \sim 50 \%$ of mice with CT26-4-1BBL or -OX40L or CT26-4-1BBL+ CT26-OX40L were completely regressed (Fig. 4). These data suggest that genetically modified tumor cells with costimulatory molecule induces the inhibition of tumor cell growth.

In this study, we developed the optimal condition for efficient lentivirus production and transduction, and identified tumor growth inhibition of genetically modified tumor cell with co-stimulatory molecule 4-1BBL or OX40L. Because it has been reported that 4-1BBL and OX40L has anti-tumor activity by various immune response including $\mathrm{T}$ cell, we should study the effect of immune response by 4-1BBL and OX40L in the tumor growth inhibition. Also, the possibility of therapeutic cancer vaccine or preventive cancer vaccine of genetically modified tumor cells are further studied.

\section{ACKNOWLEDGEMENT}

This research was supported by the Basic Science Research Program through the National Research Foundation of Korea (NRF), which is funded by the Ministry of Education, Science and Technology (2010005446).

\section{CONFLICT OF INTEREST}

No potential conflict of interest relevant to this article was reported.

\section{REFERENCES}

Allahverdiyev A, Tari G, Bagirova M, Abamor ES. Current approaches in development of immunotherapeutic vaccines for breast cancer. J Breast Cancer. 2018. 21: 343-353.

Bukczynski J, Wen T, Ellefsen K, Gauldie J, Watts TH. Costimulatory ligand 4-1bbl (cd137l) as an efficient adjuvant for human antiviral cytotoxic t cell responses. Proc Natl Acad Sci U S A. 2004. 101: 1291-1296.

Cheuk AT, Mufti GJ, Guinn BA. Role of 4-1bb:4-1bb ligand in cancer immunotherapy. Cancer Gene Ther. 2004. 11: 215-226.

Chiang CL, Coukos G, Kandalaft LE. Whole tumor antigen vaccines: Where are we? Vaccines (Basel). 2015. 3: 344-372.

Couch M, Saunders JK, O'Malley BW, Jr., Pardoll D, Jaffee E. Genetically engineered tumor cell vaccine in a head and neck cancer model. Laryngoscope. 2003. 113: 552-556.
Croft M, So T, Duan W, Soroosh P. The significance of ox40 and ox401 to t-cell biology and immune disease. Immunol Rev. 2009. 229: 173-191.

Curry WT, Jr., Gorrepati R, Piesche M, Sasada T, Agarwalla P, Jones PS, Gerstner ER, Golby AJ, Batchelor TT, Wen PY, Mihm MC, Dranoff G. Vaccination with irradiated autologous tumor cells mixed with irradiated gm-k562 cells stimulates antitumor immunity and $t$ lymphocyte activation in patients with recurrent malignant glioma. Clin Cancer Res. 2016. 22: 2885-2896.

de Gruijl TD, van den Eertwegh AJ, Pinedo HM, Scheper RJ. Whole-cell cancer vaccination: From autologous to allogeneic tumor- and dendritic cell-based vaccines. Cancer Immunol Immunother. 2008. 57: 1569-1577.

Deng J, Zhao S, Zhang X, Jia K, Wang H, Zhou C, He Y. Ox40 (cd134) and ox40 ligand, important immune checkpoints in cancer. Onco Targets Ther. 2019. 12: 7347-7353.

Dillman RO, Cornforth AN, Nistor GI, McClay EF, Amatruda TT, Depriest C. Randomized phase ii trial of autologous dendritic cell vaccines versus autologous tumor cell vaccines in metastatic melanoma: 5-year follow up and additional analyses. J Immunother Cancer. 2018. 6: 19.

Eager R, Nemunaitis J. Gm-csf gene-transduced tumor vaccines. Mol Ther. 2005. 12: 18-27.

Giaccone G, Bazhenova LA, Nemunaitis J, Tan M, Juhasz E, Ramlau R, van den Heuvel MM, Lal R, Kloecker GH, Eaton KD, Chu Q, Dunlop DJ, Jain M, Garon EB, Davis CS, Carrier E, Moses SC, Shawler DL, Fakhrai H. A phase iii study of belagenpumatucel-l, an allogeneic tumour cell vaccine, as maintenance therapy for non-small cell lung cancer. Eur J Cancer. 2015. 51: 2321-2329.

Goldman B, DeFrancesco L. The cancer vaccine roller coaster. Nat Biotechnol. 2009. 27: 129-139.

Hanna MG, Jr. Immunotherapy with autologous tumor cell vaccines for treatment of occult disease in early stage colon cancer. Hum Vaccin Immunother. 2012. 8: 1156-1160.

Hege KM, Jooss K, Pardoll D. Gm-csf gene-modifed cancer cell immunotherapies: Of mice and men. Int Rev Immunol. 2006. 25: 321-352.

Keenan BP, Jaffee EM. Whole cell vaccines--past progress and future strategies. Semin Oncol. 2012. 39: 276-286.

Kim HS, Kim-Schulze S, Kim DW, Kaufman HL. Host lymphodepletion enhances the therapeutic activity of an oncolytic vaccinia virus expressing 4-1bb ligand. Cancer Res. 2009. 69: 8516-8525. 
Klein C, Bueler H, Mulligan RC. Comparative analysis of genetically modified dendritic cells and tumor cells as therapeutic cancer vaccines. J Exp Med. 2000. 191: 1699-1708.

Lee S, Margolin K. Cytokines in cancer immunotherapy. Cancers (Basel). 2011. 3: 3856-3893.

Lipson EJ, Sharfman WH, Chen S, McMiller TL, Pritchard TS, Salas JT, Sartorius-Mergenthaler S, Freed I, Ravi S, Wang H, Luber B, Sproul JD, Taube JM, Pardoll DM, Topalian SL. Safety and immunologic correlates of melanoma gvax, a gmcsf secreting allogeneic melanoma cell vaccine administered in the adjuvant setting. J Transl Med. 2015. 13: 214.

Luo L, Lv M, Zhuang X, Zhang Q, Qiao T. Irradiation increases the immunogenicity of lung cancer cells and irradiationbased tumor cell vaccine elicits tumor-specific $t$ cell responses in vivo. Onco Targets Ther. 2019. 12: 3805-3815.

Madireddi S, Schabowsky RH, Srivastava AK, Sharma RK, Yolcu ES, Shirwan H. Sa-4-1bbl costimulation inhibits conversion of conventional cd4+ $\mathrm{t}$ cells into $\mathrm{cd} 4+$ foxp $3+\mathrm{t}$ regulatory cells by production of ifn-gamma. PLoS One. 2012. 7: e42459.

Malamas AS, Hammond SA, Schlom J, Hodge JW. Combination therapy with an ox401 fusion protein and a vaccine targeting the transcription factor twist inhibits metastasis in a murine model of breast cancer. Oncotarget. 2017. 8: 90825-90841.

May KF, Jr., Chen L, Zheng P, Liu Y. Anti-4-1bb monoclonal antibody enhances rejection of large tumor burden by promoting survival but not clonal expansion of tumor-specific cd8+ $t$ cells. Cancer Res. 2002. 62: 3459-3465.

Miguel A, Herrero MJ, Sendra L, Botella R, Algas R, Sanchez M, Alino SF. Comparative antitumor effect among gm-csf, il-12 and gm-csf-il-12 genetically modified tumor cell vaccines. Cancer Gene Ther. 2013. 20: 576-581.

Nemunaitis J, Jahan T, Ross H, Sterman D, Richards D, Fox B, Jablons D, Aimi J, Lin A, Hege K. Phase 1/2 trial of autologous tumor mixed with an allogeneic gvax vaccine in advancedstage non-small-cell lung cancer. Cancer Gene Ther. 2006. 13: 555-562.

Pan RY, Chung WH, Chu MT, Chen SJ, Chen HC, Zheng L, Hung SI. Recent development and clinical application of cancer vaccine: Targeting neoantigens. J Immunol Res. 2018. 2018: 4325874.

Perica K, Varela JC, Oelke M, Schneck J. Adoptive t cell immunotherapy for cancer. Rambam Maimonides Med J. 2015. 6: $\mathrm{e} 0004$.
Si C, Xu M, Lu M, Yu Y, Yang M, Yan M, Zhou L, Yang X. In vivo antitumor activity evaluation of cancer vaccines prepared by various antigen forms in a murine hepatocellular carcinoma model. Oncol Lett. 2017. 14: 7391-7397.

Srivatsan S, Patel JM, Bozeman EN, Imasuen IE, He S, Daniels D, Selvaraj P. Allogeneic tumor cell vaccines: The promise and limitations in clinical trials. Hum Vaccin Immunother. 2014. 10: 52-63.

Stephan MT, Ponomarev V, Brentjens RJ, Chang AH, Dobrenkov KV, Heller G, Sadelain M. T cell-encoded cd80 and 4-1bbl induce auto- and transcostimulation, resulting in potent tumor rejection. Nat Med. 2007. 13: 1440-1449.

Tang Y, Garson K, Li L, Vanderhyden BC. Optimization of lentiviral vector production using polyethylenimine-mediated transfection. Oncol Lett. 2015. 9: 55-62.

van Willigen WW, Bloemendal M, Gerritsen WR, Schreibelt G, de Vries IJM, Bol KF. Dendritic cell cancer therapy: Vaccinating the right patient at the right time. Front Immunol. 2018. 9: 2265.

Vermaelen K. Vaccine strategies to improve anti-cancer cellular immune responses. Front Immunol. 2019. 10: 8.

Vinay DS, Kwon BS. Immunotherapy of cancer with 4-1bb. Mol Cancer Ther. 2012. 11: 1062-1070.

Wang T, Wang D, Yu H, Feng B, Zhou F, Zhang H, Zhou L, Jiao S, Li Y. A cancer vaccine-mediated postoperative immunotherapy for recurrent and metastatic tumors. Nat Commun. 2018. 9: 1532 .

Webb GJ, Hirschfield GM, Lane PJ. Ox40, ox401 and autoimmunity: A comprehensive review. Clin Rev Allergy Immunol. 2016. 50: 312-332.

Weiner LM, Dhodapkar MV, Ferrone S. Monoclonal antibodies for cancer immunotherapy. Lancet. 2009. 373: 1033-1040.

Zhang H, Merchant MS, Chua KS, Khanna C, Helman LJ, Telford B, Ward Y, Summers J, Toretsky J, Thomas EK, June CH, Mackall CL. Tumor expression of 4-1bb ligand sustains tumor lytic t cells. Cancer Biol Ther. 2003. 2: 579-586.

https://doi.org/10.15616/BSL.2019.25.4.398

Cite this article as: Kim HS. Development of Genetically Modified Tumor Cell Containing Co-stimulatory Molecule. Biomedical Science Letters. 2019. 25: 398 $-406$. 